\title{
Measurement of Dynamic Mass Changes in Burning Cigarettes by Neutron Radioscopy
}

by

\section{J. S. Brenizer}

Department of Mechanical, Aerospace and Nuclear Engineering University of Virginia, Charlottesville, VA 22903

R. W. Jenkins, Jr, H. V. Lanzillotti, D. D. McRae

Philip Morris Research Centre, P.O. Box 26583

Ricbmond, VA 23261

and

C. A. Mora

Mechanical Engineering Department, Ohio Northern University, Ada, Obio 45810

\section{SUMMARY}

Neutron radioscopic images of burning cigarettes under both static and dynamic smoking conditions were analyzed with a video image processor to measure the changes occurring in the images. These changes were related to the actual mass changes occurring in the cigarette rod during the burning process. The neutron images were used to determine the deposition, movement and evaporation of pyrolysis products in the cigarette rod. In addition, the experimental data were used to calculate the mass burn rates of cigarettes. While the instantaneous mass burn rate of a smouldering cigarette can be measured with a balance, neutron radioscopy can be used to determine it under both static and dynamic smoking conditions. The results of this study, along with background information on neutron radioscopy, calibration methods and the image processing procedures, are presented.

Received: 18th April 1996 - accepted. 25th July 1996

\section{ZUSAMMENFASSUNG}

Die brennende Cigarette wurde mittels Neutronenradiographie während des statischen Abglimmens und während des Abrauchvorgangs untersucht und aufgetretene Veränderungen mithilfe einer Videokamera analysiert. Die Veränderungen waren auf Masseändernngen im Tabakstrang zurückzuführen, die während des Verbrennungsprozesses entstanden waren. Die mittels Neutronenradiographie erhaltenen Bilder sollten Aufschluß über Ablagerung, Bewegung und Verdampfung der Pyrolyseprodukte im Tabakstrang geben. Zusätzlich wurde mithilfe der experimentellen Daten die auf die Masse bezogene Abbrandgeschwindigkeit einer Cigarette berechnet. Während die momentane Verbrennungsgeschwindigkeit einer glimmenden Cigarette mit einer analytischen Waage berechnet werden kann, läßt sich mithilfe der Neutronenradiographie die Verbrennungsgeschwindigkeit sowohl in der statischen Zugpause als auch während des dynamischen Abrauchens bestimmen. Die Ergebnisse dieser Studie sowie allgemeine Hintergrundinformationen über Neutronenradiographie, Kalibriermethoden und das Bildbearbeitungsverfahren werden beschrieben. 


\section{RESUME}

La cigarette en combustion a été étudiée au moyen de la neutronographie tant à l'intervalle statique que pendant la bouffée. Les changements observés à l'aide d'une caméra video ont été analysés. Ces changements étaient liés aux variations de masse manifestées dans le boudin de tabac pendant la combustion. Les images neutronographiques devraient fournir des renseignements sur le dépôt, le mouvement et l'évaporation des produits de pyrolyse dans le boudin de tabac. En outre, les données expérimentales étaient utilisées pour calculer le taux de combustion d'une cigarette par rapport à sa masse. Tandis que le taux de combustion actuel d'une cigarette peut être mesuré à l'aide une balance analytique, la neutronographie permet de déterminer le taux de combustion engendré pendant la bouffée ou à l'intervalle statique entre deux bouffées. Les résultats de cette étude seront présentés ainsi que les informations générales sur la neutronographie, les méthodes de calibrage et le processus de traitement des images.

\section{INTRODUCTION}

Neutron radioscopy is an imaging method that is conceptually similar to X-ray radioscopy in that a beam of thermal neutrons (neutrons with energies of about $0.03 \mathrm{eV}$ ) is used to make a real-time, two-dimensional projection of an object in much the same way X-rays are used for X-ray radioscopy (1). X-rays interact with the electron cloud of an atom; the more electrons, the greater the interaction. Therefore, X-rays are attenuated to a greater extent by elements with high atomic numbers, especially the metals. Thermal neutrons, on the other hand, interact with the nucleus and this interaction is dependent on the nuclear structure of each isotope. Thermal neutrons are efficiently attenuated by only a few specific elements. Boron-10 and gadolinium are excellent thermal neutron attenuators due to their large neutron capture cross section, that is, they absorb the neutrons, removing them from the neutron beam. Hydrogen is also a good attenuator due to its large neutron scattering cross section. Neutrons are scattered out of the beam by collisions with the hydrogen nuclei. This makes neutron radiography and radioscopy useful for imaging objects containing hydrogen containing materials (water and organics) while $\mathrm{X}$-rays are generally more useful for imaging inorganic materials. Radioscopy differs from the more commonly heand term radiography. Radiography applies to a method that produces a single latent image, for example, an image on a sheet of film. Radioscopy applies to a method that generates a continuous series of electronic images in time. Radioscopy is now the accepted term for what was previously referred to as real-time radiography.
Neutron imaging is particularly applicable to cigarettes because tobacco contains a high proportion of hydrogen atoms. Hydrogen containing materials are released from and redistributed within a cigarette during burning. These processes can be measured by determining the changes occurring in the neutron image and relating such changes to actual mass changes by a suitable calibration method. This paper builds upon previous research on the measurement of density changes occurring in a burning cigarette using $\boldsymbol{\beta}$-rays and neutrons (2-5). Previous work described by BRENIZER et al. (3) showed that neutron radioscopy could be used to measure the buildup of condensible materials behind the cigarette coal for both dynamic and static smoking conditions. This paper presents major improvements to this earlier work. Specifically, the buildup of material is now measured in mass relative to tobacco, the rate of data acquisition has been increased by a factor of 5 , the mass burn rate of a cigarette can be determined, and improved data analysis techniques have led to further insights on the combustion processes. The water and other products formed from the combustion and pyrolysis of the tobacco bed are initially in a vapour state. For a puff, there is a competition between formation of the mainstream smoke aerosol and condensation on the tobacco shreds as the vapour travels down the rod and cools. This is a very rapid process occurring over a short distance in the cigarette during a puff as shown by BAKER (6). Some of the condensed material re-evaporates from the bed in the subsequent smoulder period, but the burn characteristics of the tobacco are altered. Furthermore, these condensibles are pushed ahead of the burning coal in a dynamic process involving revaporization and repartition to the smoke and the tobacco bed. The same processes occur for an unpuffed cigarette except that there is a partitioning between the sidestream smoke and the materials condensed behind the coal.

\section{EXPERTMENTAL}

The general experimental procedure can be briefly summarized as the observation of burning cigarettes in a neutron beam with a neutron imaging system. The resulting images were analyzed to determine the mass changes occurring in the burning cigarettes. This section discusses the research cigarettes examined, the smoking procedures, the imaging and image processing systems, data collection and analysis, and calibration of the system.

\section{NEUTRON RADIOSCOPY}

The neutron radioscopy system at the University of Virginia was assembled from commercially available 
equipment in a project jointly conducted by the Department of Mechanical, Aerospace and Nuclear Engineering and the Philip Morris Research Center (7). The system uses neutrons generated by the $2 \mathrm{MW}$ research reactor at the University. The reactor is a pool-type reactor in which the core is located in a pool of water for shielding. Several ports penetrate the pool wall allowing neutrons from the core to be used for experimental purposes. One beam port was modified to produce a collimated beam of thermal neutrons. The beam diameter is $15 \mathrm{~cm}$ and the thermal neutron flux is $1 \times 10^{7}$ neutrons $/ \mathrm{cm}^{2} / \mathrm{s}$. A blockhouse was constructed around the beam port to protect personnel from radiation while the neutron beam is in operation. A shuttle system was built so that objects could be moved from the neutron beam to the outside of the blockhouse, and vice versa, during experiments without closing the beam.

Objects to be viewed are placed in the neutron beam in front of a neutron imaging device. The imaging device used in these experiments was a Precise Optics (Bayshore, NY) neutron camera based on a Thomson-CSF neutron image intensifier tube (8). The camera consists of a gadolinium oxysulphide screen, an electrostatic image intensifier and a high resolution, monochrome video camera. The neutrons are absorbed by the gadolinium atoms in the screen. The gadolinium atoms emit internal conversion electrons which cause the oxysulphide coating to scintillate. In effect, the neutron images are converted to light images which are amplified by the image intensifier and viewed with the video camera. The images are produced at the standard (RS-170) video frame rate, 30 frames/s.

\section{CIGARET"TES AND SMOKING PROCEDURES}

The cigarettes used for these experiments were $\mathrm{MM} 13$ (Industry Monitor 13) research cigarettes produced by Philip Morris as a reference cigarette. IM13 cigarettes have a total length of $83.8 \mathrm{~mm}$ with a $21-\mathrm{mm}$ filter and a circumference of $24.9 \mathrm{~mm}$. The tobacco weight target is $0.794 \mathrm{~g}$ resulting in a rod density of $0.256 \mathrm{~g} / \mathrm{cm}^{3}$. The paper is Kimberly Clark 156 with a permeability of 28 $\mathrm{ml} / \mathrm{cm}^{2} / \mathrm{min}$. The mainstream total particulate material delivery is $21.3 \mathrm{mg}$ with a puff count of 9.2 as measured by the FTC method.

The IM13 cigarettes were smoked on a programmable smoking machine that is capable of producing puffs with different profiles, durations and volumes. The smoking machine consists of a computer control unit with a monitor and keyboard, and a syringe-type cylinder actuated by a stepper motor to generate the puffs. The cylinder was located on the shuttle table and the cigarettes were held in a quartz tube connected to the cylinder. When the cigarette was in place, the shuttle table was lowered into the neutron beam and data collection was started. The operation of the smoking machine was initiated by the image processing computer. A standard, $2 \mathrm{~s}, 35 \mathrm{~cm}^{3}$ puff with a rectangular profile taken once every $60 \mathrm{~s}$ was used for this work. The cigarette was lit with a flame using a lighter on an air-actuated piston. The lighter was moved into place at the end of the cigarette for the lighting puff and then retracted. In addition to runs where the cigarettes were smoked dynamically, nuns were made where the cigarettes only smouldered after the initial lighting puff.

Mass burn rates were determined by conventional methods in addition to the radioscopic technique (9). The time for each cigarette smoked in the neutron beam to consume $40 \mathrm{~mm}$ was measured using a standard video camera set up to observe the cigarettes. These linear burn rates were converted to mass burn rates by multiplying by the average mass per unit rod length. Similar measurements were made at Philip Morris Research and Devolopment (R\&D). Gravimetric mass burn rates for IM13 cigarettes were measured at Philip Morris R\&D using a balance connected to a PC for data logging. The mass burn rate was determined by calculating the slope of the mass versus time plot from the balance. Correction for the mass of the ash was required for the two methods to agree (9).

\section{DATA ACQUISITION AND COMPUTATIONAL PROCEDURES}

The radioscopic images were displayed on a monitor and digitized by the image processor. The image processing system utilized for these experiments is considerably more powerful than the original system described by BRENIZER et al. (3). The present system consists of a 386 PC with two boards from Data Translation, Inc. (Marlboro, MA): DT2861, an arithmetic frame grabber and DT2858, an auxiliary frame processor. The image processor digitized the video images into 512 by 512 picture elements (pixels) at the frame rate of $30 \mathrm{frames} / \mathrm{s}$. The luminance (brightness) values for each pixel were digitized as an integer in the range $Q$ (black) to 255 (white). Each pixel represented an area $0.48 \mathrm{~mm}$ wide by $0.45 \mathrm{~mm}$ high. A computer program was written to acquire the radio scopic data during the puffing and smouldering of cigarettes. The radioscopic data represents the attenuated response of a neutron beam due to the presence of the tobacco, paper and filter of a cigarette. As discussed above, the attenuation of a thermal neutron beam is due to scattering and absorption interactions of the neutrons with the atomic nuclei in the cigarette. For this reason, it is convenient to express the attenuation of the beam as a function of a total neutron removal coefficient, $\mu$. Since cigarettes have a relatively small thickness, the attenuated 
response is reasonably approximated by Beer's law:

$$
I=I_{0} \exp (-\mu t)
$$

where $I$ and $I_{0}$ are the attenuated and initial neutron intensities, respectively, and $t$ is the thickness of the object under analysis. The neutron removal coefficient has the units of $\mathrm{cm}^{-1}$. To calibrate the system, $I$ and $I_{0}$ values for samples of tobacco, the charcoal-like pyrolysis char, the wrapping paper, and the ashes were measured in the neutron beam. The mass and thickness of the samples were accurately known. The neutron removal coefficients were calculated using Beer's law. Table 1 presents the results from these measurements.

\section{Table 1.}

Calculated total neutron removs' coefficients for cigarette materials standardized for mass density, $\rho$. The units for $\rho$ are $\mathrm{g} / \mathrm{cm}^{3}$.

\begin{tabular}{l|c}
\hline \multicolumn{1}{c|}{ Material } & $\mu / \rho\left(\mathrm{cm}^{2} / \mathrm{g}\right)$ \\
\hline Tobacco (IM13) & $2.428 \pm 0.025$ \\
Dried tobacco $(\mathrm{M} 13)$ & $2.391 \pm 0.024$ \\
Char & $0.606 \pm 0.015$ \\
Cigarette paper & $2.265 \pm 0.028$ \\
Ashes & $0.359 \pm 0.015$ \\
\hline
\end{tabular}

Knowing the removal coefficient for any given object, it is possible to calculate its thickness from the radioscopic data as follows:

$$
t=\frac{\ln \left(\frac{I_{0}}{I}\right)}{\mu}
$$

However, neutron radioscopy of cigarettes becomes much more attractive when we consider the calculation of two other related quantities. First, the determination of the relative density-thickness, $\delta$, has been shown to be a useful measure of the condensibles deposited in the rod during burning (3). The density-thickness has units of $\mathrm{mg} / \mathrm{cm}^{2}$ and is expressed as:

$$
\delta=t \rho
$$

or

$$
\delta=\frac{\ln \left(\frac{I_{0}}{I}\right)}{\mu} \rho
$$

where $\rho$ is the mass-density of the object. Second, the mass can be easily calculated from the expression:

$$
m \cdot \operatorname{tp} A
$$

where $A$ is the projected area of the object being radiographed. For a digital image consisting of $i$ rows and $j$ columns of pixels, the mass in each pixel is given by:

$$
m_{t J}=\frac{\ln \left(\frac{I_{0}}{I}\right)_{i J}}{\mu} \rho A_{i J}
$$

where $m_{i, j}$ is the mass of the object imaged in the $(i, j)$ th pixel and $A_{i j}$ is the area of the pixel. The total mass of the object can be obtained by summing over all of the pixels in the object:

$$
M \cdot \sum_{i} \sum_{j} m_{i j}
$$

Eq. 7 has proven to be very useful in determining the mass burn rates of cigarettes under both smouldering and puffing regimes.

Data acquisition was made general enough to determine both density-thickness and total mass results from the experiments. To decrease the noise due to the neutron beam fluctuations, the real-time images were integrated (frame averaged) with respect to time with the image processor. A twenty frame integration was found to be a good compromise between noise reduction and the loss of time resolution. The luminance values for the portion of the image containing the cigarette were then stored to the hard disk of the computer. This process was repeated throughout each experimental run. The time expended on integration and data storage was less than 4 seconds. In the previously reported work, this time was about 20 seconds (3). Therefore, the new system makes it possible to obtain a considerable amount of data on the dynamics of burning cigarettes. Faster computers and, especially, image processing boards would reduce this time further. Each 8-bit pixel luminance was stored as a single byte. Programs were written to convert the stored luminance values to mass or density-thickness results based on the equations discussed above.

A simplification used in the data analysis program was to assume that the cigarette paper was tobacco. This assumption makes a very small error in the determination of burn rates since the paper represents less than $8 \%$ of the total mass of the cigarette and its neutron removal coefficient is close to that of tobacco. On the other hand, the assumption represents a very useful simplification as opposed to the rather complicated pixel identification and geometric correction procedures required to determine 
the real mass of the paper.

The key point to remember is that hydrogen atoms in a cigarette are lost to pyrolysis and combustion products during the burning process. In these experiments, as the hydrogen atoms were lost from a region in a cigarette corresponding to a given pixel, the pixel changed to higher luminance values, that is, the pixel changed to lighter shades of grey. The image processor measured and recorded the luminance values for each pixel in the cigarette as a function of time. Luminance values were calibrated to actual tobacco mass units by recording the luminance values for tobacco samples of known density and calculating the neutron attenuation coefficient from Beer's Law. Cigarette mass burn rates (MBRs) were then calculated from the change in mass with time.

\section{RESULTS AND DISCUSSION}

Initial experiments were performed by lighting the cigarette before it was lowered in the neutron beam and recording the pixel data for only the tobacco rod. The MBR results from these experiments were in slight disagreement with the MBRs measured by the other methods. Subsequently, it was determined that there was a measurable mass loss in the entire rod caused by the hot gases from the lighting flame. Also, the buildup of water and other conderasibles in the filter section was not negligible. These effects were taken into account by changing the data collection procedure to the one described above.

Mass burn rates were determined by applying Eq. 6 to every pixel in the defined region of interest (the cigarette) and calculating the total mass, Eq. 7, with respect to time. The slope of a plot of the change in mass with respect to time provides the mass burn rate. Figure 1 shows the change in mass of an IM13 cigarette as a function of time for smouldering and puffing conditions. The slopes of both curves, the MBR values in the legend, were calculated using a linear regression. The burn rate of a puffed cigarette is, of course, higher than that of a smouldering cigarette because of the tobacco burned during the puffs. The burn rate of the puffed cigarette between the puffs is practically the same as the smouldering burn rate. The cigarette returns to the smouldering regime after the forcing action of the puff ends.

Tables 2 and 3 represent a summary of the MBR values for the different methods for static and dynamic burn, respectively. The MBRs are averages from five or more cigarettes. All of the techniques agree closely.

Previously published work using neutron radioscopy to investigate burning cigarettes focused on the behaviour of the water and other smoke materials that condense in the rod behind the coal (3). The new method described in this

Table 2.

Static (smoulder) mass burn rates.

\begin{tabular}{lc|c|c}
\hline \multicolumn{1}{c|}{ Method } & $\begin{array}{c}\text { Burn time } \\
(\mathrm{min} / 40 \mathrm{~mm})\end{array}$ & $\begin{array}{c}\text { Linear burn rate } \\
(\mathrm{mm} / \mathrm{min})\end{array}$ & $\begin{array}{c}\text { Mass burn rate } \\
(\mathrm{mg} / \mathrm{min})\end{array}$ \\
\hline & 8.8 & 4.5 & 59.9 \\
$\begin{array}{l}\text { Burn time (PM R\&D) } \\
\text { Gravimetric (PM R\&D) }\end{array}$ & & & 56.8 \\
$\begin{array}{l}\text { Burn time (UVA) } \\
\text { Radioscopic }\end{array}$ & 8.8 & 4.5 & $59.9 \pm 1.0$ \\
\hline
\end{tabular}

Table 3.

Dynamic (puffed) mass burn rates.

\begin{tabular}{|c|c|c|c|}
\hline Method & $\begin{array}{l}\text { Burn time } \\
\text { (min/40mm) }\end{array}$ & $\begin{array}{c}\text { Linear bum rate } \\
(\mathrm{mm} / \mathrm{min})\end{array}$ & $\begin{array}{c}\text { MBR } \\
(\mathrm{mg} / \mathrm{min})\end{array}$ \\
\hline Burn time (UVA) & 6.8 & 5.9 & $77.6 \pm 4.7$ \\
\hline Radioscoplc & & & $79.5 \pm 2.7$ \\
\hline
\end{tabular}




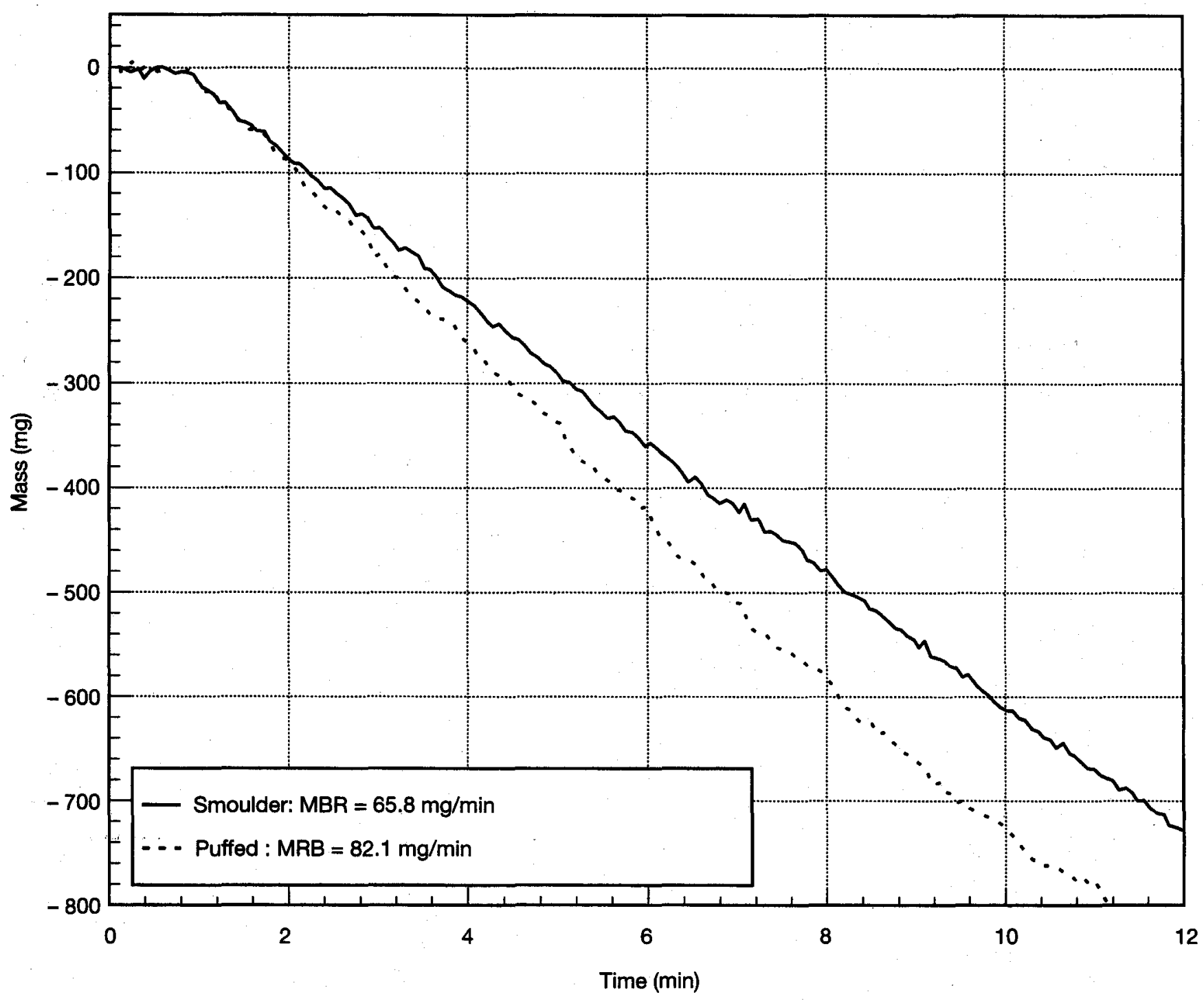

Figure 1.

Change in mass as a function of time for an IM13 cigarette for smouldering and puffing conditions as measured by neutron radioscopy. The slopes of the lines are the mass burn rates.

paper permits considerable improvements over this earlier work. In particular, more data points are recorded and the results are reported as actual mass. Following the presentation used by JENKINS et al. (2) Figure 2 shows a plot of the change in mass in a $4.8 \mathrm{~mm}$ (10 pixels long) section of the tobacco rod near the filter as a function of time for smouldering and puffed cigarettes. This plot was constructed by adding together all of the mass changes in the individual pixels contained in the section. It was necessary to use this approach in the earlier work to reduce the noise in the data. The plot in Figure 2 is essentially identical to the results presented by HAWKESWORTH et al. (1) and JENKINS et al. (2). The plot shows that as a cigarette smoulders there is an initial, slow but steady loss in mass in the section. This is caused by volatile constituents, including water, being swept off of the tobacco by the flow of gases down the rod from the coal. Radioscopic data taken on unlit cigarettes, with and without puffing, do not show a similar mass loss, so it is not caused solely by water loss from a conditioned cigarette exposed to dryer room air. As the coal approaches the section, the mass begins to increase slightly due to distillation and pyrolysis products depositing on the tobacco adjacent to the coal. Finally, as the coal burns into the section, the mass decreases precipitously due to the loss of material containing hydrogen atoms. For a puffed cigarette, the mass loss behaviour is similar to the one for a smouldering cigarette when the coal is far from the $4.8 \mathrm{~mm}$ section being monitored. As the coal approaches, there are sudden increases in the mass of the section. These jumps are the result of mainstream materials being deposited on the tobacco in the section during a puff. The decrease in the section mass between puffs is due to the more volatile materials evaporating and leaving the 


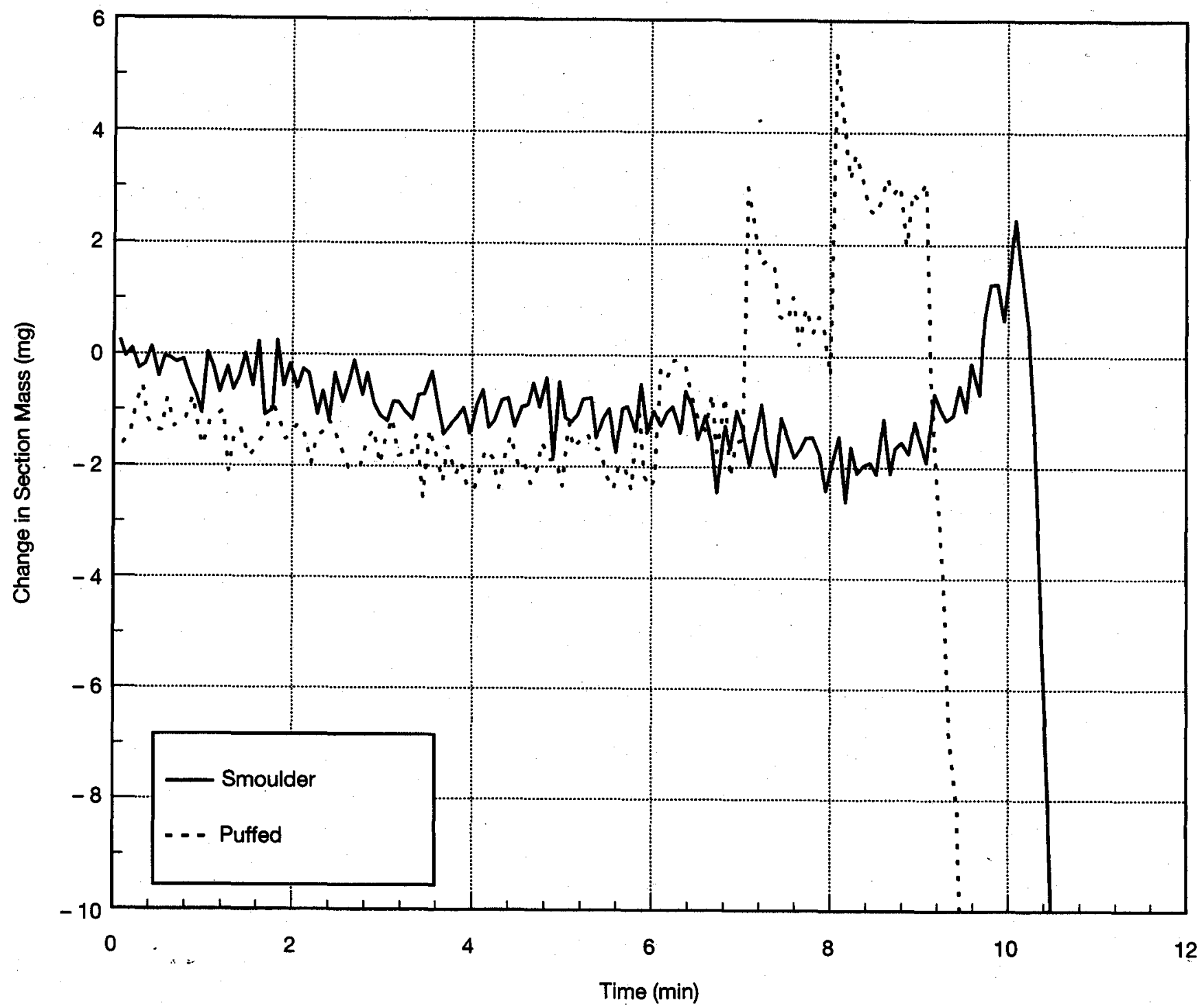

Figure 2.

Change in mass as a function of time for a $4.8 \mathrm{~mm}$ (10 pixels long) section of the tobacco rod located near the filter for an IM13 clgarette under smouldering and puffing conditions.

section. The extent of this effect is only within the closest two or three puffs, or within about $20 \mathrm{~mm}$ from the char line. Beyond this distance the mainstream smoke is well formed and less material is available for deposition and condensation. Preliminary work on cigarettes with different papers indicates that the paper porosity plays a major role in determining the amount of material condensing behind the coal during smoulder and the amount of the material that evaporates after a puff.

The radioscopic data can be analyzed in other ways to extract additional information about the processes occurring in the burning cigarette. For example, the mass loss profiles for each $4.8 \mathrm{~mm}$ section along a cigarette are very similar differing mainly in their time axis. The new methods presented in this paper allowed a more detailed exploration of this similarity between sections. The mass information for each one pixel wide slice $(0.48 \mathrm{~mm})$ of the cigarette rod was calculated. As was expected from the 10 pixel wide section data, these one pixel wide slices were very similar. The time scale for each slice was moved to place the zero time at the point at which the mass loss of a given segment had achieved one-half of its maximum value. This is approximately the location of the paper char line in physical space. The data for all of the slices in a cigarette were then averaged. The average slice data for smouldering and puffed cigarettes are presented in Figure 3. Note that time is positive for the regions that have burned and negative for those that have not. That is, the unburned rod is in the negative portion of the time scale. Just to the left of zero time the mass change is greater than zero due to the deposition of water and other condensible materials on the tobacco behind the coal. The deposition effect of the puffs at every minute can be seen in the curve for the puffed cigarette. Another important observation is that the mass change is less than zero for times less than 4 minutes even though the coal is far away. 


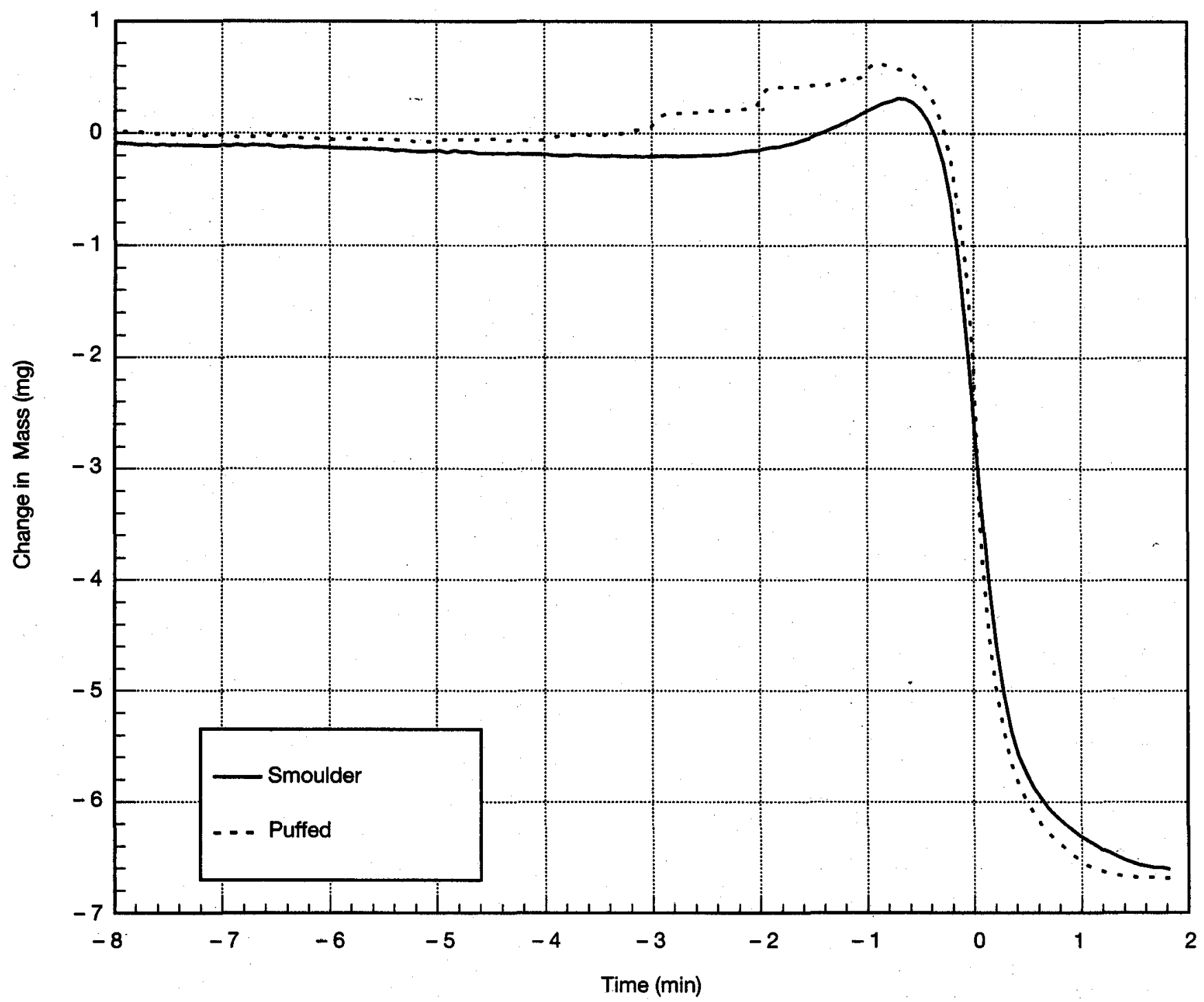

Figure 3.

Change in mass as a function of time for an average slice (one pixel wide section) for an IM13 cigarette under smouldering and puffing conditlons. Before averaging the slice data, the time scale for each slice was moved to place the zero time at the point at which the mass loss of a given segment had achieved one-half of its maximum value. This is approximately the location of the paper char line in physical space. Time is positive for the regions that have burned and negative for those that have not.

As discussed above, this is caused by the effect of the lighting puff and the flow of gases down the rod that is present even for smouldering cigarettes.

The mass change plot for a smouldering cigarette shown in Figure 3 can be modelled by considering three processes: the pyrolysis of tobacco; condensation/deposition of pyrolysis products; and evaporation of water in the rod. These are the three processes that affect the hydrogen atom content of the tobacco behind the coal. The equations describing fractional mass change due to these processes determined by fitting the data for $t<0$ were: for evaporation $\quad f_{\text {evap }}=-0.098 \mathrm{e}^{0.38 t}$

for condensation

$$
f_{\text {cond }}=-0.655 e^{3.22 t}\left(1-e^{-1.792}\right)(
$$

The total fractional mass change is the sum of these equations:

$$
f=f_{\text {pyr }}+f_{\text {evap }}+f_{\text {cond }}
$$

The modelling of the data was performed only for times 


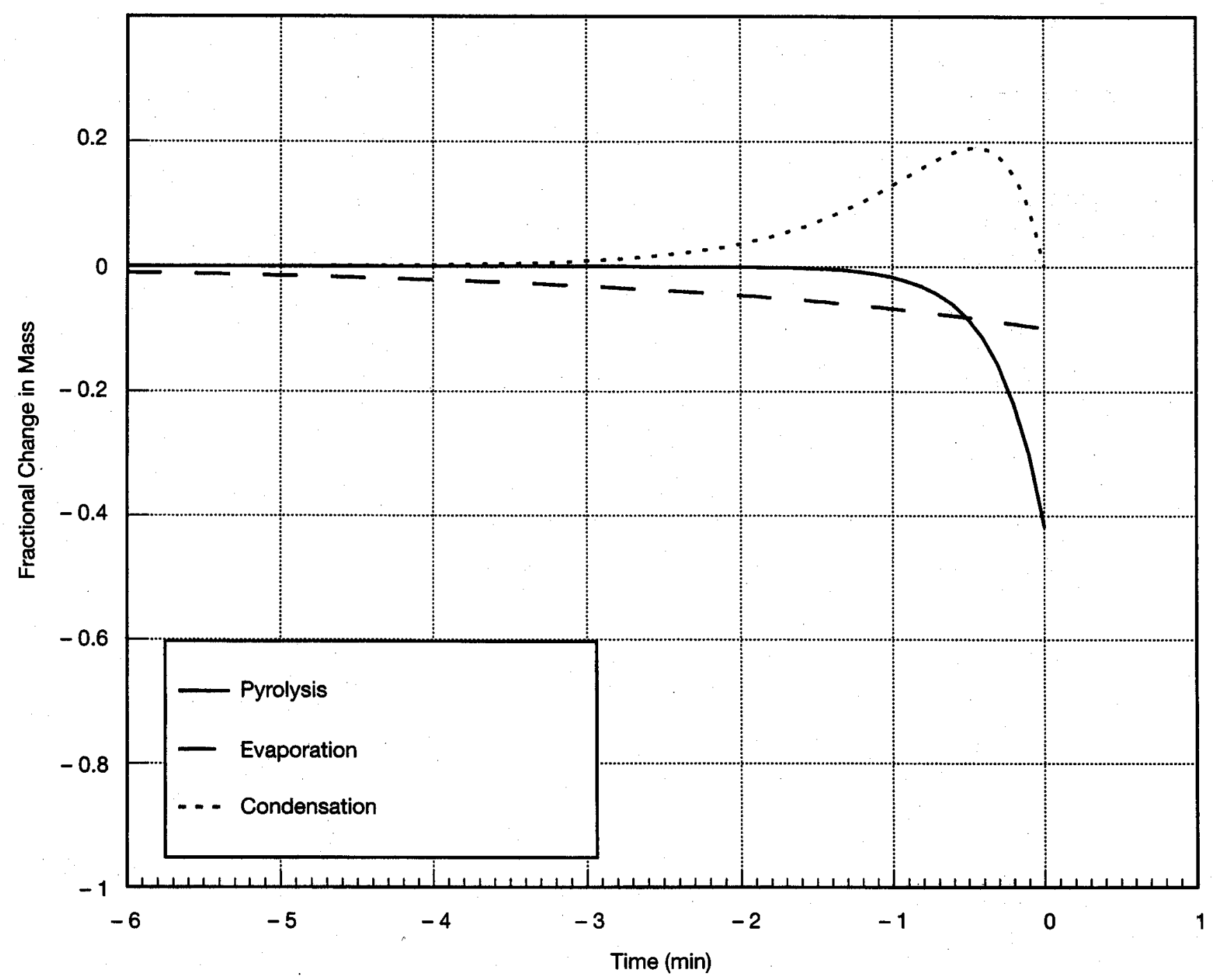

Figure 4.

Behaviour of the equations representing the pyrolysis, evaporation and condensation processes occurring in a smouldering cigarette plotted as the fractional change in mass versus time.

less than zero, i.e., for the unburned portions of the rod. For times greater than zero, these processes should cease to exist and the combustion of the remaining char material should now become the major mass loss process. The form of the equation for condensation is a combination of two competing processes, condensation generation by pyrolysis and condensate evaporation. The condensate evaporation differs from the evaporation of water. The behaviour of the three functions is shown in Figure 4 and a comparison of the summed equations and the actual fractional mass change for a smouldering cigarette is shown in Figure 5. The behaviour of the three processes shown in Figure 4 is in agreement with our general conception of what is happening in a smouldering cigarette. There are a number of items that require further research. This includes the addition of an equation describing char combustion and the extension of the model to times greater than zero.

\section{CONCLUSIONS}

The advantages of examining cigarettes with neutron radioscopy are apparent in the information obtained about the details of the burning process. The technique yields mass burn rates under both static and dynamic smoking conditions. The technique could be extended to measure mass burn rates of cigarettes lying on a surface independent of mass loss of the surface material. Neutron radioscopy also permits the examination of the mass changes occurring in small areas of the cigarette with respect to time and position. These mass changes include the buildup and movement of condensible materials, and the changes due to combustion and pyrolysis. The application of neutron radioscopy to measure these processes in experimental cigarettes can lead to a better understanding of the changes produced by different construction features. 


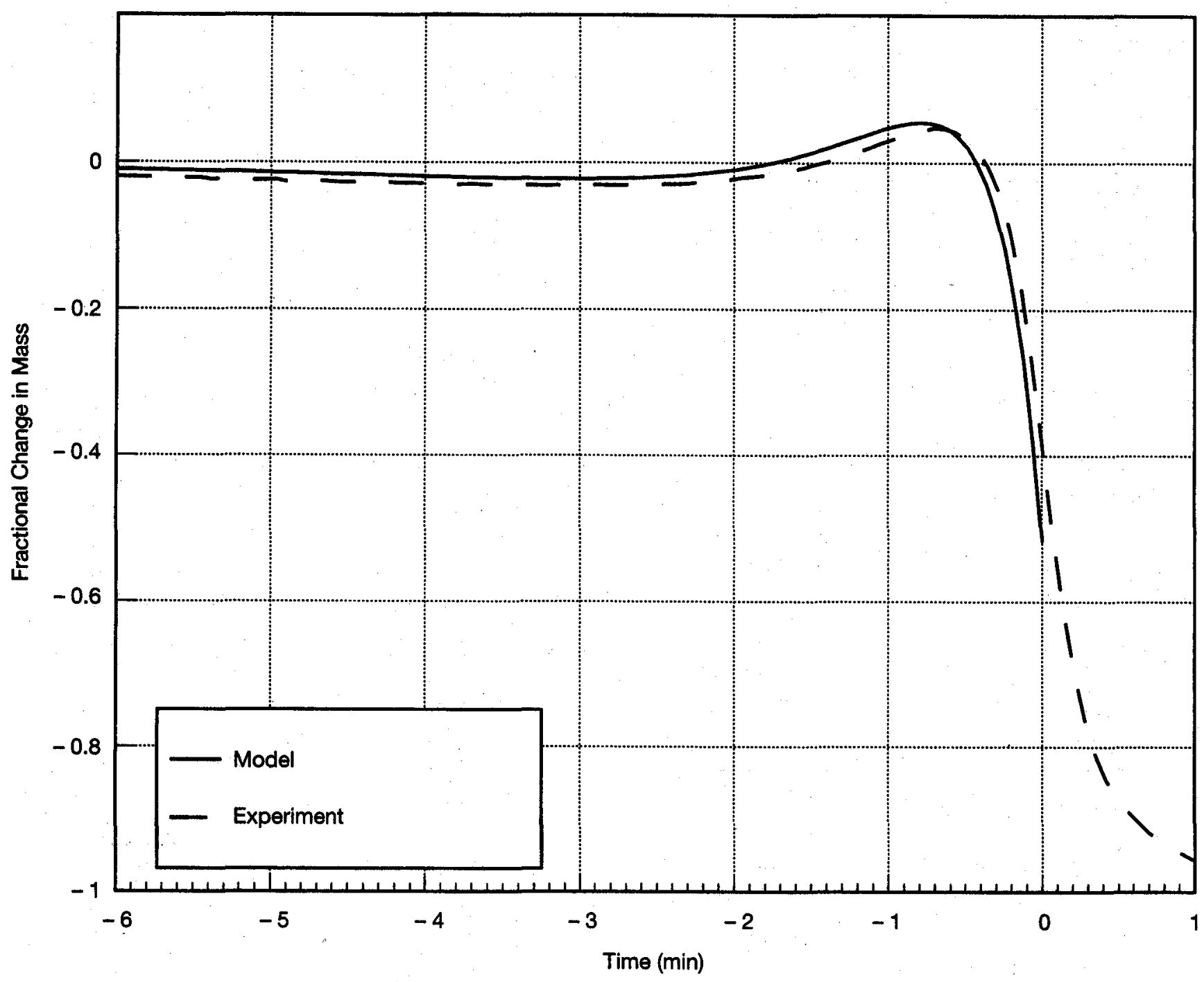

Figure 5.

Comparison of the model predictions to the actual fractional mass change for a smouldering cigarette.

\section{REFERENCES}

1. Hawkesworth, M. R., and J. Walker: Basic Principles of Thermal Neutron Radiography; in: Neutron radiography: Proceedings of the First World Conference, edited by J. P. Barton and P. von der Hardt, D. Reidel, Dordrecht, Netherlands, 1983, pp. 5-21.

2. Jenkins, R. W. , Jr., A. F. Frisch, J. G. MacKinnon and T. G. Williamson: Cigarette smoke formation studies IV. The dynamic measurement of axial density of a burning cigarette; Beitr. Tabakforsch. 9 (1977) 67-71.

3. Brenizer, J. S., K. W. Tobin, J. M. Hylko, D. D. McRae and R. W. Jenkins, Jr.: Quantitative measurement of equivalent water density in a burning cigarette; Materials Evaluation 45 (1987)1310-1314.
4. Brenizer, J. S., M. F. Sulcoski, K. W. Tobin, Jr., R. W. Jenkins, Jr., and D. D. McRae: Evaluation of filter behavior by neutron radiography; J. Aerosol Sci. 18 (1987) 311-320

5. Brenizer, J. S., M. F. Sulcoski, R. W. Jenkins, Jr., D. D. McRae and R. H. Newman: Observations of density variations in tobacco rods by neutron radiography; Beitr. Tabakforsch. 14 (1987) 21-28.

6. Baker, R. R.: Temperature variation within a cigarette combustion coal during the smoking cycle; High Temperature Sci. 7 (1975) 236-247.

7. Brenizer, J. S. and M. F. Sulcoski: Real-time neutron radiography at the University of Vinginia; Atomkernenergie Kerntechnik (Suppl.) 44 (1984) 958-963. 
8. Verat, M. H. Rougeot and B. Driard: Neutron image intensifier tubes, in: Neutron Radiography: Proceedings of the First World Conference, edited by J. P. Barton and P. von der Hardt, D. Reidel, Dordrecht, Netherlands, 1983, pp. 601-602.

9. Resnik, F. E., W. G. Houck, W. A. Geiszler and J. E. Wickham: Factors affecting static burning rate. Tob. Sci. 21 (1977) 103-107.
Authors' address:

Philip Morris Research Center

P.O. Box 26583

Richmond,

$V A, 23261$,

USA 